\title{
Digital Transformation in the Mining Sector: Exploring Global Technology Trends and Managerial Issues
}

\author{
Yuliia Lazarenko ${ }^{1 *}$, Olga Garafonova ${ }^{1}$, Vyktoriia Marhasova ${ }^{2}$, and Nataliia Tkalenko ${ }^{3}$ \\ ${ }^{1}$ Kyiv National Economic University named after Vadym Hetman, Management Department, 03057, \\ 54/1 Pr. Peremogy, Kyiv, Ukraine \\ ${ }^{2}$ Chernihiv Polytechnic National University, Department of Theoretical and Applied Economics, \\ 14035, Chernihiv, Shevchenko str.,95, Ukraine \\ ${ }^{3}$ Chernihiv National University of Technology, Public Administration and Business Management \\ Department, 14035 Chernihiv, Ukraine
}

\begin{abstract}
Across the industries, management faces increasing pressure to make digital transformation a strategic priority and embrace the opportunities offered by digitalization, and the mining sector is not an exception in this regard. Whereas it is recognized that within the mining industry digitalization will be a driving force that has a great potential to transform the nature of companies and their interaction with stakeholders at every stage of the value chain, there seems to be a lack of an understanding as to what should be investigated from a managerial perspective for the successful undertaking of the digital transformation initiatives. The paper aims to provide a descriptive overview of the global industry trends with regard to digital technologies in the mining sector, as well as develop a conceptual digital transformation framework that is intended to improve business' digitization processes for the mining companies by identifying the core managerial areas on which attention should be focused in order to ensure effective implementation of the digital transformation strategy. These main action fields, along with optional additional dimensions could be further elaborated depending on the organizational context and industry environment, and should be taken into consideration when planning and organizing activities directed at delivering effective digital transformations.
\end{abstract}

\section{Introduction}

To thrive in a highly dynamic and complex environment, it is necessary for modern businesses to monitor and analyze industry technology trends on an ongoing basis, and develop future-focused innovation-oriented activities that allow a company to adapt to the change and uncertainty. Nowadays the digital transformation process is considered as one of the most important factors central to the development of the mining sector, along with

\footnotetext{
${ }^{*}$ Corresponding author: yuliia.lazarenko@kneu.ua
} 
other relevant trends that are likely to shape the mining of the future. Digitalization has become a business imperative, leveraging the latest technology advances to improve operational processes in order to ensure strategic competitiveness, reduce risks, and increase business performance. However, it remains difficult for mining operators to decide which digital technologies are the most relevant to their experience, current needs, priorities, and challenges. This paper is aimed to provide a descriptive overview of digital technologies in the mining sector which are relevant at the firm level and develop a managerial framework for organizations in order to describe key dimensions that should be considered for a successful digital transformation strategy implementation.

In this study digitalization in the mining industry is considered as a process of adopting technologies, digital devices, methods, systems, digitized data, and advanced analytics in an appropriate way in order to achieve desired strategic organizational objectives and business outcomes, such as costs reduction, operational performance improvement, and a general transformation of mining practice towards making it safer and more efficient and sustainable.

This research focuses on defining a theoretical basis for a deeper understanding of the current global trends with regard to digitalization that are likely to shape the mining of the future. The paper discusses the importance of organizational adoption of digital innovations for the mining operators and describes the mechanisms by which it can be carried out. It also includes a review of the significant drivers and barriers related to digital transformation in the context of the mining industry. Additionally, managerial implications are presented which can be conceptualized at the firm level in order to integrate new digital technologies into the operating model to undertake successful digital transformation.

\section{Materials and Methods}

In today's business environment which is characterized by a dynamic and radical pace of change as well as a high degree of uncertainty that implies both opportunities and challenges, the global mining sector is under pressure. A review of current data reporting shows the trend towards declining productivity in the industry - according to statistics, worldwide mining operations are nowadays as much as 28 percent less productive than a decade ago [1]. With the collapse in mining profitability over the past years, the industry players are seeking to raise their productivity. Despite the need for technological advances which are playing an increasing role in situations of knowledge-intensive, innovationdriven, and efficiency-seeking organizational changes, the nature of mining has remained nearly the same for decades [2]. In matters related to innovation capacity building, the mining sector is different in many ways from other industries in the global economy. Evidence shows that main innovation activity challenges specific to the mining operators relate primarily to increased production costs, a short-term focus on exploration, the difficulties of gaining access to the right type of knowledge and technologies, as well as a traditional restrictive mindset which causes conservative attitude towards innovation [3]. With regard to the digital transformation the following key challenges that hinder the rate of digital technologies implementation in the mining sector can be identified: the inability of technology providers to facilitate the implementation of their solutions, difficulties in adapting current business models to agile principles, and a general tendency within the sector to focus on project outputs instead of sustainable business outcomes [4].

This paper aims to characterize the innovation environment in the mining sector, with particular emphasis on the importance of digital technologies adoption for the mining operators. Based on the latest thematic studies and industry reports global technology trends that will likely determine the future of the mining industry are analyzed in the study, as well as the main drivers and barriers of digital transformation are highlighted. The paper is 
structured as follows: first, a descriptive overview of the global technology trends of Industry 4.0 for the mining industry is provided. Then, based on a review of the existing literature and thematic research, the impact of digital technologies adoption on different stages of the mining value chain is presented. As a result of the study, through the integrated approach, a conceptual framework that is intended to improve business' digitization processes for the mining companies is developed in order to define essential organizational determinants that support the successful digital transformation, and explore significant industry-related factors which underpin and strengthen these processes.

\section{Results and Discussion}

The challenges that the companies of the mining sector face over the past decades, were taking place in the context of the technological, social, and structural economic shifts which were brought about, to a large extent, by disruptive digital innovations across industries. Achieving a breakthrough on productivity performance demands rethinking the business model that brings a corporate strategy and operations together in a framework which places values of sustainability orientation, social responsibility, and innovation activity at the heart of the decision-making process. The potential to achieve such a breakthrough within the industry could be ensured through digital and technology innovations that are able to transform key aspects of mining, strengthen the technological dimension of production activities, and contribute to the innovation development for sustainable outcomes and improvements in productivity. In the realities of the Industry 4.0, also known as Smart Industry or the Fourth Industrial Revolution, innovation-focused activities can be considered as the only way to survive in the competitive market. The situation caused by the COVID-19 pandemic can serve as an example which clearly shows that innovative companies are able to continue their business due to innovation and technologies even under difficult and challenging global economic conditions [5]. All of this underscores the need to examine industry-specific factors which influence the innovation performance in the mining sector in a digital and networked economy and emphasizes the relevance of the appropriate integrated application of modern digital technologies that had become available for the mining industry players, as well as relevant tools and techniques of digital management for enhancing the innovative capacities of mining companies and strengthening their strategic competitiveness.

In the Ernst \& Young Global Limited annual report (2021) which examines the top 10 business risks and opportunities for metals and mining, digital effectiveness is identified as one of the major risk factors facing the mining operators [6]. Many of the issues surrounding digital changes have become "business as usual" for the larger miners worldwide. As shown by the latest thematic studies and industry reports, a scope for technology diffusion and the adoption of digital innovations depends on the production rate of the sector players. Thus, larger mining companies appear to select and apply digital technologies suitable to their experience, needs, and values, whereas minor operators are often not as extensively involved in such innovation-oriented activities and may require other solutions related to digital transformation tailored to their capabilities [7]. Given that in a modern business environment digital technologies have been identified as a critical enabler to address the sector's productivity and margin challenges, the exploring of essential organizational determinants that support the successful digital transformation is nowadays an area of growing interest among both academics and practitioners.

Despite the mining sector differs in many ways from other industries in the global economy, extractive industries are also likely to be significantly impacted by disruptive innovations with regard to digital transformations in the context of Industry 4.0, and the Fourth Industrial Revolution that is having a wide-ranging influence on the business 
environment, creating both opportunities and challenges. Digital transformation as a broad concept refers to the changing process of a company or its business model due to the implementation of digital technologies [8]. In this context, digitalization in the mining sector refers to the use of computerized or digital devices or systems, digitized data, computational power, technological advances in analytics and artificial intelligence that are to reduce costs, improve business productivity, and transform mining practices [7;9]. These technologies include advanced robotics, digital twins, big data, artificial intelligence and advanced analytics, mobile computing, wearable technology, internet of things, and autonomous and near-autonomous vehicles [10].

While the modern digital technologies are and will keep deeply affecting the different areas of the business, including extractive industries, questions related to how and to what extent digital innovations could be adopted in the mining sector should be examined more thoroughly. Taking into account the industry's particularities, the results of research based on the co-word analyses and text-mining techniques with suitable algorithms have shown that the key digital technologies relevant to the mining companies include automation, robotics, internet of things, big data, real-time data, machine learning, artificial intelligence, and $3 \mathrm{D}$ printing [7].

According to the survey results, which were presented in 2020 (The Future of Jobs Survey 2020, World Economic Forum), the pace of digital technologies adoption is expected to accelerate in the mining and metal sector [11]. The findings indicate the willingness to implement innovative technologies among companies from the mining and metals industries. The adoption of big data analytics, internet of things and connected devices and robots, nonhumanoid (industrial automation, drones, etc.) remain high priorities for the industry players - about $90 \%$ of the surveyed companies expressed their likelihood to adopt such technologies by 2025 (Figure 1). However, there has also been a significant rise in interest for cloud computing, encryption and cyber security, and artificial intelligence (e.g. machine learning, neural networks, NLP).

\section{Technology adoption in the mining and metals sector}

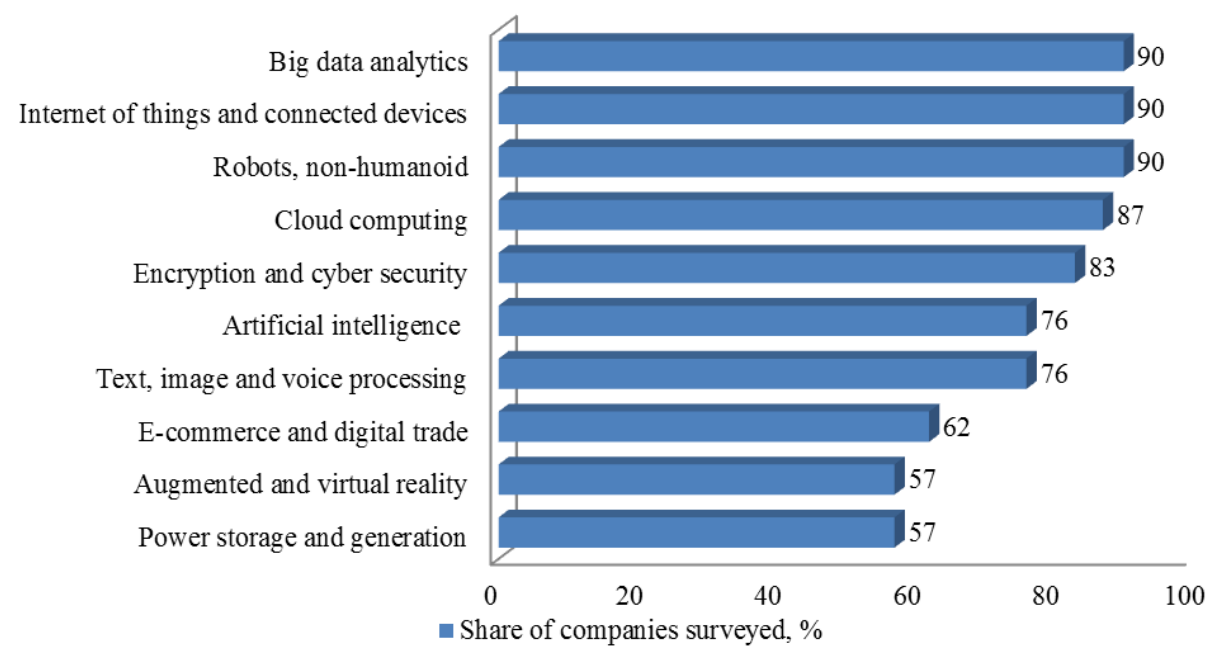

Fig. 1. Digital technologies likely to be adopted in the mining and metals sector by 2025 Source: The Future of Jobs Survey 2020, World Economic Forum [11]

In recent years, mining companies have already realized the necessity to adapt to changing circumstances and incorporate new technologies in their operations to improve 
efficiency, decision-making system, and create a safer working environment. As a result, many large industry actors have begun their digital transformation towards intelligent operations. As it was defined in the industry report by Deloitte (2021), intelligent mining should not be conceived as solely a "digital mine", but rather as a broader set of technology-oriented activities which aim at implementing organizational transformations [12]. Intelligent mining is and will keep affecting not only the internal factors and components of the organizational context of mining operators, such as the way decisions are made, the skills, knowledge and capabilities that are needed, etc., but also the external linkages related to strategic collaborative relationships and networked interactions, i.e. how to engage with the workforce, local communities, and the other stakeholders to promote corporate responsibility and sustainable development. From a technical perspective, intelligent mining could be considered as an integrated system that comprises automated mining equipment as the core, integrated digital communication network as the carrier, intelligent design and production management software system as a platform, and innovation-driven monitoring and control tools and techniques for the operational process management through real-time and dynamic control, which promotes the maximization of operational safety and efficiency, and contributes to economic and societal benefits of mining that responded to practical needs of companies and communities [13].

According to Deloitte's vision, the intelligent mine is a connected and integrated, automated but human-centered system, that comprises three key domains: digital core technologies (ERP Platform, IT / OT Architecture, Integrated Data Platform), intelligent mining solutions with regard to different stages of the mining value chain, such as exploration and development, mining, processing, logistics, sales and marketing, and human-centered managerial approach $[4 ; 12]$. The integrated intelligent mining system is intended to optimize the whole value chain or ecosystem, and at the firm level to improve integration across all the functions in the operational process and ensure that staff and managers throughout the organization are empowered to make effective decisions in order to implement a digital transformation strategy.

It is recognized that digital technologies enable a fundamental shift in vision, strategy, operating model, business skills, and capabilities in the mining industry. The widespread adoption of automated mining equipment, integrated digital communication network, intelligent design and production management software systems, advances in analytics, from machine learning to improved statistical techniques coupled with appropriate management support will provide the basis for the maximization of value. The impact of digital technologies adoption on different stages of the mining value chain is presented in the Figure 2.

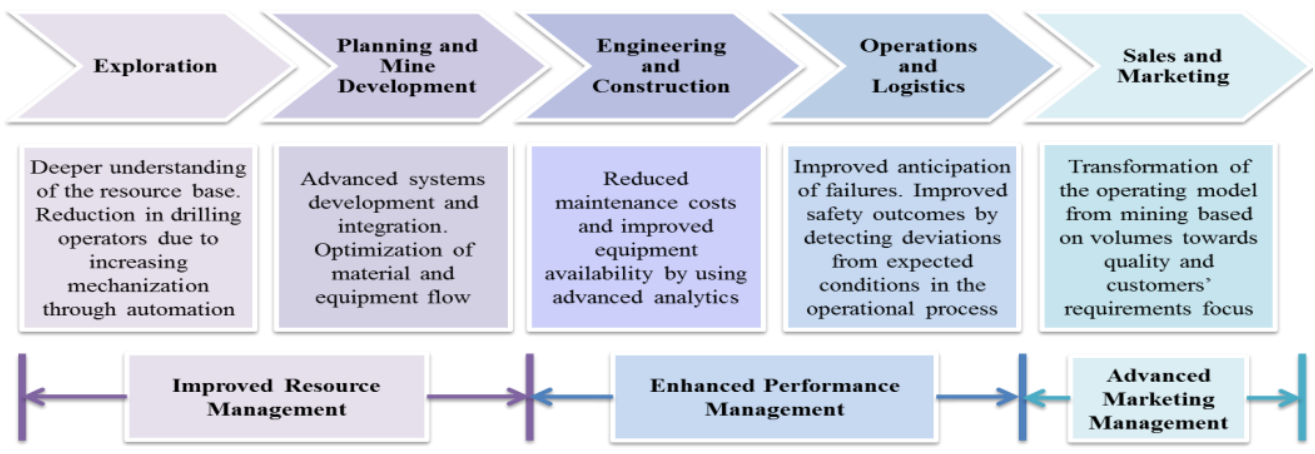

Fig. 2. The impact of the digital technologies implementation on different stages of the mining value chain

Source: Developed by authors adapting [2; 14-17] 
Thus, for mining companies the digital technologies have the potential to provide new directions for the transformational changes in the way they do business, identify new ways to manage variability and enhance productivity, and hence develop a new paradigm for growth and development. We share the opinion that to ensure integrated approach digital technologies should be embedded whole across the mining value chain. From this perspective, the focus areas for a business to be able to leverage digital technology and drive sustainable development encompass the following $[2 ; 10]$ :

- the operational process optimization (by means of increased mechanization through automation that can lead to the costs reduction and operating discipline improvement);

- the enhanced performance management (by monitoring of real-time performance versus plan which may contribute to the optimization of operations across the whole supply chain);

- the improved decision-making system (including a deeper understanding of the resource base by adopting statistical methods and online sampling, optimization of material and equipment flow, improved anticipation of failures, reduced breakdowns, as well as improved equipment availability by using advanced analytics).

According to the findings of the international consulting firms' reports, many digital transformation programs fail primarily due to insufficient attention given to the managerial aspects of the digital strategy implementation, such as lack of necessary business skills and leadership competencies, poor cross-functional collaboration, difficulties in integrating new principles to current business models, challenges related to establishing an appropriate digital culture which includes experimentation, collaboration, employee involvement, and training. These conclusions emphasize the need to develop a conceptual digital transformation framework that is intended to improve business' digitization processes for the mining companies by identifying the core managerial areas on which attention should be focused in order to ensure successful implementation of the digital transformation strategy (Figure 3).

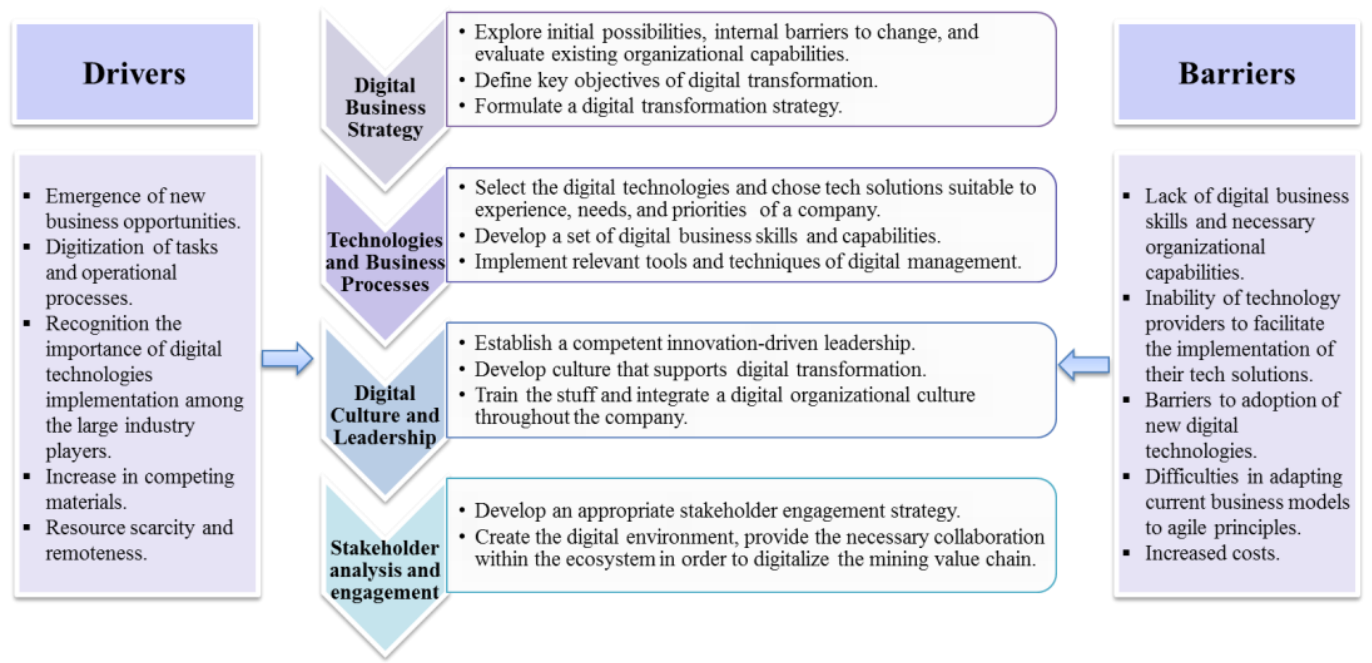

Fig. 3. A conceptual digital transformation framework in the context of the mining sector Source: Developed by authors adapting [18-20]

With reference to the summarized literature, four key action fields or managerial dimensions can be distinguished to be included in a cross-industry digital transformation framework: digital business strategy, technologies and business processes at the firm level, 
digital culture and competent leadership, as well as stakeholder analysis and engagement. We share the view that these main areas, along with optional additional dimensions that could be further elaborated depending on the organizational context and industry conditions, should be taken into consideration when planning and organizing activities aimed at delivering effective digital transformations. From a managerial point of view, effective implementation and achievement of expected results of digital transformation at the firm level requires significant organizational shifts to be able to locate and integrate digital technologies in the core of the organization. In order to achieve the successful digital transformation in the organization, it is essential to establish an effective strategy for incorporation and adoption of new digital tools which should be based on a proper understanding of the current business needs, and tailored to specific business requirements, firm's priorities, and the scale of a company's operations.

\section{Conclusions}

Although there is a widespread recognition of the importance of digital transformation with regard to extractive industries, the timelines, as well as organizational and managerial aspects for such a transformation still are not sufficiently clear and need to be better understood at all levels. To provide a fully integrated and automated mining supply chain, the digital innovations should not be perceived solely as technology activities, but rather as an undertaking that encompasses all the aspects of business, and requires a fundamental shift in a company's vision, values, strategy, business model, planning and operational processes and workflows, as well as organizational capabilities. Although mining has always been marked by a conservative approach to innovation-oriented activities, particularly to investing in research and development, the implementation of digital technologies may lead to new and currently unknown opportunities which could be core to the industry's operational performance. Based on the findings of the study it can be concluded that increased adoption of specialized digital technologies, data analytics and automation has the potential to improve safety and environmental outcomes, increase productivity, and is resulting in new business models across the entire mining value chain.

\section{References}

1. A. Lala, M. Moyo, S. Rehbach, and R. Sellschop, Productivity in mining operations: Reversing the downward trend (AusIMM Bulletin. Australasian Institute of Mining and Metallurgy, 2016)

2. H. Durrant-Whyte, R. Geraghty, F. Pujol, and R. Sellschop. How digital innovation can improve mining productivity (McKinsey \& Company, 2015)

3. M. Kurkkio, J. Frishammar, P. Söderholm, T. Ejdemo. Mapping the Nordic Mining and Metal Industry for the Purpose of Enhancing and Developing its Innovative Capability (Paper presented at Luleå tekniska universitet, 2014)

4. Intelligent Mining. Delivering Real Value (Deloitte Touche Tohmatsu Limited, 2018)

5. P. Khan, S. K. Johl, and S. K. Johl. Business Strategy and The Environment, 1 (2021)

6. P. Mitchell, A. van Dinter, R. Stall. Top 10 business risks and opportunities for mining and metals in 2021 (Ernst \& Young Services (Pty) Limited, 2021)

7. L. Barnewold, B. G. Lottermoser. International Journal of Mining Science and Technology, 30(6), 747 (2020) 
8. J. Reis, M. Amorim, N. Melão, P. Matos. Digital transformation: a literature review and guidelines for future research. In: Trends and advances in information systems and technologies (Cham: Springer International Publishing, 2018)

9. F. Sánchez, P. Hartlieb. Mining, Metallurgy \& Exploration, 37, 1385 (2020)

10. R. Gosine, P. Warrian. Digitalizing extractive industries: state-of-the-art to the art-ofthe-possible: opportunities and challenges for Canada (Munk School of Global Affairs, University of Toronto, Innovation Policy White Paper Series, 2017)

11. The Future of Jobs Report. World Economic Forum (Geneva, Switzerland, 2020)

12. Tracking the trends 2021 (Deloitte Touche Tohmatsu Limited, 2021)

13. APEC Study on Innovation Mining Industry of Sustainable Growth (APEC Policy Partnership on Science, Technology and Innovation, Chengdu, China, 2019)

14. V. Correia, C. Keane, and R. Evans. Action plan to close skill gaps and enhance existing education and training programmes Deliverable 3.4 (Technical Report. Spanish Geological Survey. Instituto Geológico y Minero de España, IGME, 2021)

15. J. Camus. Management of Mineral Resources: Creating Value in the Mining Business (Society for Mining, Metallurgic and Exploration Inc., Colorado, 2002)

16. N. T. Arndt, L. Fontboté, J. W. Hedenquist, S. E. Kesler, J. F. H. Thompson, D. G. Wood. Geochemical Perspectives, 6 (1), 1 (2017)

17. CSIRO. Mining Equipment, Technology and Services: A Roadmap for unlocking future growth opportunities for Australia (CSIRO, Melbourne, Australia, 2017.

18. J. Bumann, and M.K. Peter. Action Fields of Digital Transformation - A Review and Comparative Analysis of Digital Transformation Maturity Models and Frameworks, pp. 13-40, in: Aeschbacher Marc; Hinkelmann, Knut \& Verkuil, Arie 2019: Digitalisierung und andere Innovationsformen im Management. Innovation und Unternehmertum, Band 2 (Edition Gesowip, Basel, Schweiz, 2019)

19. B. Calzada Olvera. Mineral Economics, 9 (2021)

20. Digital Transformation Initiative. Mining and Metals Industry (World Economic Forum. Geneva, Switzerland, 2017) 